\title{
La práctica de la verdad en contextos hostiles: ecos de un modo de existencia.
}

\section{The practice of truth in hostile circumstances: echoes of a mode of existence.}

Esta obra está bajo una Licencia Creative Commons Atribución 4.0 Internacional. DOI: $10.32870 /$ sincronia.axxiii.n75.3a19

\section{Edwin Augusto Correa Cetina}

Universidad de San Buenaventura

corcet@hotmail.com

(COLOMBIA)

Recibido: $13 / 08 / 2018$

Revisado: $17 / 10 / 2018$

Aprobado: 01/11/2018

\section{RESUMEN}

El problema de la verdad y su sentido constituye un tema central del pensamiento filosófico. Pues, la manifestación de la verdad, responde históricamente a las necesidades e intereses humanos demarcados en épocas concretas. De ahí que sean los discursos de poder los instrumentos configuradores de la realidad capaces de comunicar proposiciones razonables en contextos hostiles. En esta vía, nace el objetivo de este trabajo que es el examinar diferentes discursos de verdad teniendo como hilo conductor, la noción de parresía. Este objetivo coloca en contexto las modalidades del decir veraz, la parresía a partir de un caso colombiano y la inhabilidad de enunciar la verdad en escenarios públicos.

Palabras clave: Verdad. Parresía, Mentira. Humor. Sabio.

ABSTRACT 
The problem of truth and its meaning is a central theme of philosophical thought. Well, the manifestation of truth, historically responds to human needs and interests demarcated in specific times. That is why the discourses of power are the instruments that configure reality and that can communicate reasonable propositions in hostile contexts. In this way, the aim of this work is born, which is to examine different discourses of truth, having as a guiding principle, the notion of parrhesia. This objective puts in context the modalities of truthful saying, parrhesia based on a Colombian case and the inability to enunciate the truth in public settings.

Keywords: Truth. Parrhesia, Lie. Humor. Wise.

\section{Introducción}

La necesidad de producir conocimiento y verdad han configurado múltiples contextos históricos que han entretejido la estructura de la vida misma. En sus comienzos, la existencia del hombre primitivo estuvo cobijada por miedos, supersticiones e incertidumbres. La especulación arcaica avaló el primer intento de comprensión, implantándose la confusión y el desacierto en su más pura expresión. Con el tiempo, surge el deseo de conocer las causas materiales de la existencia, configurándose así uno de los intentos racionales que busco condensar la explicación material de las presencias ónticas a partir de un principio originario denominado (arché).

Este modelo cosmológico fue teorizado por un séquito de filósofos antiguos, quienes presentaron múltiples visiones arquetípicas con las que intentaban deducir explicaciones racionales, firmes y lógicas. Sin embargo, este nuevo proceso racional no estuvo del todo exento de ser una nueva lógica especulativa que poco a poco se desliga de la metafísica. Al respecto Jaeger dice: “El punto de partida de los pensadores naturalistas del siglo VI era el problema del origen, la physis, que dio su nombre a la totalidad del movimiento espiritual y a la forma de especulación a que dio lugar" (2001, p.144).

Este movimiento intelectual fue puntualmente impulsado por un grupo de filósofos presocráticos que, al posarse en tierras extranjeras, experimentan observaciones fascinantes. Con 
sus apreciaciones filosóficas y observaciones aparecen las nuevas explicaciones del origen del cosmos. Es así como en plena época antigua, la semilla científica empieza a crecer paulatinamente para estrechar el abismo de los errores especulativos:

Hay algo fundamental nuevo en la manera que tuvieron los griegos de poner al servicio de su último problema, relativo al origen y la esencia de las cosas, las observaciones empíricas que aceptaron del Oriente y enriquecieron mediante las suyas propias, así como en el modo de someter al pensamiento teórico y causal el reino de los mitos fundado en la observación de las realidades aparentes del mundo sensible, los mitos relativos al nacimiento del mundo. En este momento asistimos al nacimiento de la filosofía científica (Jaeger, 2001, p.145).

Según Jaeger, este nacimiento científico estaba rodeado de postulaciones metafísicas. Para explicar esta idea, el filólogo toma de ejemplo a Anaximandro y lo reconoce como el pensador de la antigüedad capaz de mancomunar estos dos enfoques opuestos. Dice Jaeger: en el ámbito científico, este presocrático desarrolla un hábil análisis matemático de las proporciones geográficas, aporte que dio como resultado el primer mapa de la tierra. En cuanto a su concepción metafísica, este presocrático concibe la idea de ápeiron: la define como lo ilimitado, evidenciando con dicho postulado la transgresión de los límites físicos. (Cf, Jaeger, 2001, p.145).

Con el nacimiento del saber científico, la racionalidad se superpone ante las supersticiones, comenzando el periodo de gestación y maduración de la verdad. Aunque es de advertir, que utilizar el término de verdad descuidadamente implica cierto riesgo, pues el mismo Nietzsche comprendió que todo lo que ha sido presentado en la realidad como verdad, es en el fondo historia del error mismo.

El hombre siempre ha intentado aferrarse a lo que cree veraz y a pesar del método y la objetividad con la que intente tratar la realidad, esto no exime que, el saber construido en el presente sea tratado y considerado como saber mitológico en el futuro. Sin embargo, se le debe mucho a aquellas creaciones fantásticas que han sido fuentes históricas de inspiración para 
formulación de teorías consistentes. Pues sin ellas, la consolidación de la verdad científica y política no habría sido factible.

Es por ello que el afianzamiento de la veracidad científica ${ }^{1}$ necesita apoyarse de un método experimental organizado que cimiente efectivamente la objetividad de su conocimiento. En cambio, la verdad política dependerá de la capacidad individual de enunciar y denunciar lo falaz desde la dádiva de discurso franco, pues: "el deber de decir lo verdad es un imperativo sagrado" (Derrida, 1997, p.7). Resaltar aquí la presencia de lo veraz en estos dos ámbitos, no deja de lado que ésta pueda ser enunciada en otras esferas del saber.

Lo cierto, es que el acceso a la verdad ha dependido de las épocas, de los alcances técnicos y de las capacidades racionales del hombre, considerándose previamente que: "la verdad debe tener conexiones esenciales con los intereses humanos" (Davidson, 1997, p.146). Por eso, el deseo de anteposición ante lo falaz es lo que ha consolidado los mecanismos dialécticos en función del progreso, creencias y usos discursivos. Pues, la facultad cognitiva del decir y su convicción en el actuar han configurado tensiones riesgosas para quien pretende enunciar la verdad. Por tanto, el problema radica en entrever ¿Cómo se desarrolla la parresía en diferentes escenarios públicos y en su divergencia con otras modalidades del decir veraz? Para tal propósito, es necesario situarnos en primer lugar en una perspectiva histórica tradicional que brinde la posibilidad de articular la verdad con el hablar. Para ello, comenzaremos en la época antigua, precisamente en Grecia, para luego empalmar el concepto de verdad con algunas vivencias de verdad contemporáneas.

\section{El Hablar claro como identidad propia}

Para hacer tolerable y posible nuestra existencia fue necesario mover la vida en favor de verdades funcionales. Sin embargo, es necesario preguntar, ¿qué pasaría si ante lo que denomino, y sé que es verdadero se impone la mentira? Una probable discusión sobre este problema gira alrededor del

\footnotetext{
1 "La verdad es una colección de verdades; y estas verdades constituyentes están en manos de los mejores métodos de investigación y comprobación disponibles como cuestiones de hecho, métodos que son, cuando se los reúne bajo un único nombre, la ciencia" (Davidson, 1997, p.147).
} 
sujeto de verdad; él se contrapone a la mentira y puede optar por callar, apelar, o decirlo todo sin disimulo. La mentira premedita intención, ella vela la realidad, creando una situación ofuscante para aquel quien tiene la convicción de ser el acreedor de la verdad. Es de resaltar que la mentira es engaño, nada tiene que ver con el error:

[...] se puede estar en el error, engañarse sin tratar de engañar, y por consiguiente, sin mentir [...] cualquiera que enuncie un hecho que le parezca digno de ser creído o que en su opinión sea verdadero, no miente, aunque el hecho sea falso² (Derrida, 1997, pp.1-2).

A pesar, de que la veracidad se derive de la convicción, esto no evita que exista un choque de convicciones que dificulten juzgar lo que es realmente verdadero, por esta razón la realidad es un malentendido.

Por ello, dentro de este marco conceptual, resaltaremos al último Foucault, filósofo francés destacado por realizar una interesante exegesis sobre la verdad a partir del concepto de parresía ${ }^{3}$; dicha noción, Foucault la estudia como "discurso veraz en el orden de la política" (2009, p. 23). Dice Foucault que quien posee esta aptitud, es capaz de decirlo todo con explicita franqueza. Por esta razón, el enunciado de la verdad no da lugar a manifestaciones expresivas sutiles y, ni a discursos tenues. Pues, la parresía más que ser una mera cualidad, es una virtud que infiere el deber de cuidar de sí y del otro. El parresiasta, se exhibe a sí mismo como el guerrero fiero de la verdad, pues cuando la enuncia no espera reconocimiento, solo asume una responsabilidad peligrosa y mortal.

Según Foucault, esta virtud de decirlo todo, se contrapone a la del enunciador performativo, pues éste se distingue por adaptarse al ritmo convencional de la sociedad, accediendo siempre a la voluntad del hacer cuando escucha la orden ajena del decir. Este es el rasgo característico de los determinismos modernos institucionales. En ellos, el hombre venial posa su seguridad, y con ella

2 "San Agustín lo destacaba también: no hay mentira, por más que se diga, sin la intención, el deseo o la volu ntad explícita de engañar (fallendi cupiditas, voluntas fallendi)" (Derrida, 1997, pp.1-2).

3 "La palabra parresía aparece por primera vez en la literatura griega en Euripides( c. 484-407 a.C.), y recorre todo el mundo literario griego de la antigüedad desde finales del siglo $\vee$ a.C. [...]. Parresía es traducida al castellano por franqueza. Parresioázomai es hacer uso de la parresía, y el parresiatés es alguien que utiliza la parresía, es decir alguien que dice la verdad (Foucault, 2004, p. 35). 
también anula la posibilidad de reinventarse, crecer y enunciar cosas desafiantes y veraces. Con la parresía aparece una carga de enunciados que proyectan una serie de hechos que, "van a afectar, de una manera u otra, el modo de ser del sujeto" (Foucault, 2009, p. 84): he aquí la denominada dramática del discurso verdadero, la cual tiene que ver con el análisis de las circunstancias enunciadas en la disertación, y en la manera como ellas inquietan el ser del disertante.

En el mundo heleno antiguo, la parresía era una actitud universal a la que puede compadecer cualquier ciudadano griego ${ }^{4}$ : consistía en la de tomar la palabra en plena asamblea política. Allí cualquiera, sin necesidad de tener un cargo gubernamental tiene la libertad: "de ponerse de pie, hablar, decir la verdad o pretender decirla y afirmar decirla. Eso es la parresía: una estructura política" (Foucault, 2009, p.88). La parresía, como decir veraz para sí y para otros, constituía el anhelo desinteresado de cuidar la salud del Estado y la de sus congregantes. Un ejemplo de esta caracterización, es cuando Sócrates deambula por la polis conversando con los ciudadanos señalándoles sus errores con razonamientos irónicos: “invitándoles a ocuparse de la sabiduría, la verdad y la perfección de sus almas" (Foucault, 2004, p. 51).

La parresia debe entenderse como un ordenado y explícito discurso de oposición. Por eso, cautela con el hombre que ejerce su poder político a voluntad y capricho, pues corre el riesgo de padecer la aversión del parresiasta, en cuyo discurso, competente levantará contundentes críticas que, de algún modo pone cierto límite al autoproclamado derecho del tirano de gobernar despiadadamente.

Un ejemplo de este acontecimiento lo resalta Foucault, cuando cita el episodio 14 de la constitución de los atenienses. Allí se relata, como Atenas podría perder la libertad si entrega sus derechos a los designios del tirano, Pisístrato. Este autócrata, intenta ejercer su soberanía en nombre propio, y apoyado de una guardia personal pretende tomar el poder. Esta acción impulsa al

\footnotetext{
${ }^{4}$ El ciudadano griego es considerando diferente al forastero, solo en relación a su preparación en cuanto a educación recibida y reforzada en el uso del lenguaje, por esta razón: "Entre un extranjero a una ciudad donde la raza se mantiene sin tacha y, aun cuando la ley lo convierta en ciudadano, su lengua seguirá siendo sierva; él no tendrá derecho a decirlo todo [ouk ekheiparrhesíam no tiene la.parrhesía] (Foucault, 2009, p.88).
} 
viejo Solón a intervenir en la Asamblea como ciudadano libre. En el lugar, Solón acude vestido con coraza y escudo, con este gesto pretende evidenciar lo que sobreviene: Pisístrato, al armarse de una guardia personal, está considerando a los atenienses enemigos contra los cuales tendrá que luchar. En plena Asamblea, el discurso parresiasta de Solón se despliega, y con profundas palabras dice: "Soy más sabio que quienes no han comprendido los malos designios de Pisístrato, y más valeroso que quienes los conocen y callan por miedo"5 (Foucault, 2010, p. 91). La disertación de Solón realza la denuncia en contra tirano y fortifica una crítica espontanea a sus coetáneos. Al final, el Consejo se dirige a Solón y pone en tela juicio su cordura6, a lo que Solón contesta: "Si yo estoy loco, vosotros lo estaréis dentro de poco tiempo [...] cuando la verdad salga a la luz" (Foucault, 2010, p. 91).

Este ejemplo de parresia política difiere de la practicada por Sócrates, puesto que, este filósofo nunca enuncio la verdad desde el estrado de una asamblea pública tal como lo hizo Solón. La razón de esta actitud el mismo Sócrates la expresa así: "no he hecho política, no me subí a la tribuna porque de haberlo hecho, estaría muerto" (Foucault, 2010, p. 88). Esto no significa que Sócrates hubiese renunciado a la política y mucho menos que lo haya hecho por miedo a la muerte, lo hizo porque consideraba importante el cuidado de si y de los otros: "al estar muerto no habría podido [...] ser útil a sí mismo y a los atenienses" (Foucault, 2010, p. 95). Al estar vivo, Sócrates consideró que haría cosas positivas, útiles y provechosas, sintiendo que este era el designio con el cual había sido investido.

Por eso, la práctica de la verdad y la justicia ocupó todos los espacios de la vida de Sócrates, un ejemplo de ello fue durante el régimen de los treinta tiranos. En las habituales funciones rotativas de los ciudadanos griegos, se le encomienda a Sócrates y a tres ciudadanos más arrestar a León de Salamina. El filósofo considera que el arresto era por una acusación injusta y decide no

\footnotetext{
5 "La doble parrhesia de Solón en este caso: parrhesia con respecto a Pisístrato, ya que, mediante el gesto que [realiza] al llegar con coraza y armadura a la Asamblea, muestra, debido [a] eso, lo que aquél está haciendo. Develan la verdad de lo que sucede y al mismo tiempo dirige un discurso de verdad a la Asamblea al criticar a quienes no comprenden, pero al criticar también a [los] que, aunque comprenden, se callan" (Foucault, 2010, p. 91).

6 "El parresiasta se torna en y aparece entonces como el charlatán impenitente, aquel que no sabe moderarse o, en todo caso, que no es capaz de ajustar su discurso a un principio de racionalidad y un principio de verdad" (Foucault, 2010, p. 28).
} 
participar en él: "yo manifesté, no mediante palabras sino mediante actos [oulogo al ergo), que la muerte no me inquietaba en absoluto" (Foucault, 2010, p. 95).

Otro acontecimiento, donde Sócrates apela a la lo justo y verdadero, lo vive en el juicio de los generales de las Arginusas. A ellos se les acusa de no levantar los cadáveres después de la batalla. Este acontecimiento fue leído como un acto de impiedad. Sócrates es el único que vota en contra del deseo común y argumenta: "Yo estimaba que mi deber consistía en arrostrar el peligro con la ley y la justicia en vez de asociarme con vosotros en vuestra voluntad de injusticia por temor a la prisión y a la muerte" (Foucault, 2010, p. 94).

Dos momentos en lo que Sócrates enfrenta el peligro con probables consecuencias de muerte. Uno más lo vive al final de su vida en su propio juicio: todo transcurre en Atenas, cuando Querofonte, uno de los discípulos de Sócrates pregunta al Oráculo ¿Quién es el hombre más sabio de todo Atenas? -El Oráculo responde-, Sócrates es el más sabio de todos. Inquieto por la réplica del Oráculo, Sócrates comienza su propio ejercicio de indagación filosófica. En las calles de Atenas confronta a políticos, poetas y trabajadores. Percibe al interpelarlos, que el hombre de la política es solo un hombre de fama; que los poetas, recitan bellas palabras, pero desconocen su sentido; y que los trabajadores, sorprendentemente encuentra que ellos conocen más que lo que el mismo Sócrates conoce, sin embargo: "sean los hombres de Estado ignorantes y los artesanos sabios, tienen en común el hecho de creer conocer las cosas que no saben" (Foucault, 2010, p. 99). De esta pesquisa no solo consigue que: "sabe más que los otros, al menos en el sentido que conoce su propia ignorancia" (Foucault, 2010, p. 99), sino que de ello también consigue enemigos que lo llevan a un juicio póstumo a partir de dos acusaciones. Una, que corrompía la juventud, y otra que, no creía en los dioses, habiéndolos sustituido por adoraciones demoniacas: "Estos dos cargos se llamaban y apoyaban el uno al otro, porque tenían por fundamento común el crimen de ultraje a la religión" (Platón, 1871, p. 44).

El juicio, de Sócrates desemboca con su muerte, sin embargo, en lo últimos momentos de su vida se hace celebre para la filosofía el pronunciamiento de Sócrates a uno de sus discípulos: 
-Critón, debemos un gallo a Asclepio--. Dumézil, aporta una interpretación de esta declaración, cuando concibe el gesto del sacrificio como agradecimiento a la cura de una enfermedad social que, rotula a las enunciaciones erradas y a los prejuicios como verdades concluyentes ${ }^{7}$. Con el fenecimiento de Sócrates, desaparece una figura parresiasta, para quien la verdad y la justicia significo todo.

En este punto, es claro que la acción parresiasta implica riesgos que traen como consecuencia póstumas represalias; aunque también puede que tras el discurso de verdad no pase nada, pues el agraviado no se siente abrumado por lo que escucha y simplemente deja pasar. Lo cierto es que cuando el parresiasta expresa la verdad cisura su relación con ese otro, puesto que en su manera de hablar no aparecen adornos retóricos del discurso. Pues, un retorico utiliza palabras complacientes para seducir a sus oyentes, y con ello crea y mantiene relaciones vinculantes. Para cumplir este objetivo, los retóricos suelen usar mascaras del lenguaje que expresan lo opuesto de lo que realmente saben, creen y piensan:

La retórica es un arte, una técnica, un conjunto de procedimientos que permiten al hablante decir algo que tal vez no sea en absoluto lo que piensa, pero que va a tener por efecto producir sobre aquel a quien se dirige [...] La parresía establece, pues, entre quien habla y lo que dice un lazo fuerte, necesario, constitutivo, pero abre bajo la forma del riesgo el vínculo entre el hablante y su interlocutor (Foucault, 2010, p. 32).

Ahora bien, hasta aquí se ha dado cuenta del significado de la parresía, la actitud del parresiasta y la diferencia entre parresía y retórica. También es necesario resaltar que el decir veraz no es potestad exclusiva del parresiasta, pues existen otras modalidades del decir veraz con notables diferencias.

7 -Critón debemos un gallo a Asclepio- Este enunciado ha tenido diferentes interpretaciones, una de ellas la brinda Robin: él cree que el sacrificio es un agradecimiento por haber curado el mal del alma, que consiste en haber coexistido con el cuerpo. Otra interpretación la ofrece Nietzsche, cuando dice: "Estas ridículas y terribles 'últimas palabras' significan, para quien sepa escucharlas: 'Oh, Critón, la vida es una enfermedad" (Foucault, 2010, p. 112). Lamartine converge con Nietzsche cuando en sus versos proclama: "¡Hágase un sacrificio a los dioses liberadores, dice. iMe han curado! - ¿De qué?, pregunta Cebes. -De la vida" (p. 111). 


\section{Cuatro modalidades fundamentales del decir veraz: más una perspectiva en contravía.}

Foucault, describe cuatro modalidades del decir veraz, cada una posee características singulares. La primera figura es el profeta, según el filósofo galo, este personaje se reconoce y es reconocido por otros como alguien que dice la verdad. El profeta es un intermediario de una voz que habla desde otro lugar, se configura como intérprete y revelador. El profeta, por lo general supone ser el portavoz de la palabra de Dios. Nietzsche en el Ecce Homo (2004), por ejemplo, tiene una apreciación opuesta sobre el profeta, el piensa que son simplemente: "horribles híbridos de enfermedad y voluntad de poder que las personas llaman fundadores de religiones" (Nietzsche, 2004, p. 9).

La segunda figura es el sabio, él es opuesto al profeta, porque habla en nombre propio. Él no es portavoz, a pesar de que puede estar inspirado por una deidad o una tradición, no por ello, el sabio deja de estar presente en su decir veraz (Cf. Foucault 2010, p. 32). Los sabios son moderados en lo que dicen y hacen: "se callan y no se ocupan [de] taprágmata (los asuntos de la ciudad)" (Foucault, 2009, p. 32). En contravía a la rotulación arcaica de esta palabra, Nietzsche, la re significa como una fuerza telúrica que fue desvirtuada por los decadentes: "Estar enfermo, volverse loco, provocar los síntomas de perturbación, esto significaba hacerse más fuerte, más sobrehumano, más temible, más sabio" (Nietzsche, 2000b, p. 62). He aquí, el concepto autentico de sabio, sus características originales han investido la figura del Zaratustra.

La tercera figura es el profesor o técnico, él es transmisor del saber práctico, no corre riesgo en su tarea. Resalta Foucault, que el profesor habla en nombre propio a favor de una tradición. Sin embargo, siendo el hombre del saber hacer, en muchas circunstancias su trabajo resulta inútil, así lo describe Nietzsche:

Un profesor, que por ejemplo desee conducir a un escolar hasta el mundo griego - difícil de alcanzar e infinitamente lejano- por considerarlo como la auténtica patria de la cultura: todo eso será verdaderamente inútil, cuando el mismo escolar una hora después coja un 
periódico o una novela de moda, o uno de esos libros cultos cuyo estilo lleva ya en sí el desagradable blasón de la barbarie cultural actual (Nietzsche, 2000a, p. 47).

Esta no es la única crítica que Nietzsche resalta, pues en términos de su época y no muy alejada de la nuestra, critica esta figura al afirmar que en el campo académico: "faltan los talentos realmente inventivos, faltan los hombres verdaderamente prácticos, o sea, los que tienen ideas buenas y nuevas, y saben que la auténtica genialidad y la auténtica praxis deben encontrarse necesariamente en el mismo individuo" (Nietzsche, 2000a, p. 51).

La cuarta, es la ya resaltada figura del parresiasta. Él no es ni profeta, ni sabio, ni profesor, el habla por sí mismo de forma clara y franca. En su discurso adopta críticas con el riesgo de desatar la ira de su enemigo.

\subsection{Perspectiva en contravía: ¿El sacerdote, una modalidad del decir veraz?}

El parresiasta, habla por sí mismo y asume las consecuencias de su decir, cuestiona situaciones relevantes desvelando la situación presente. Una figura más y opuesta a la del parresiasta, es el sacerdote que, amparado en los libros de la revelación se siente convencido de su decir veraz. Esta condición, le hace suponer que tiene un aire de supremacía blindada de cualquier cuestionamiento:

El sacerdote quiere dejar bien sentado que es el tipo superior del ser humano, que domina -incluso sobre aquellos que tienen el poder en las manos-, que es invulnerable, inatacable: que él es la fuerza más potente de la comunidad, que no hay absolutamente ninguna forma de sustituirlo o subestimarlo (Nietzsche, 2000b, p. 123).

El parresiasta es un sujeto preocupado por el vivir del contexto inmediato, le interesa razonar en favor de la verdad por el bien de si y de los otros. En cambio, el sacerdote como cualquier otro funcionario, tiene mayor interés en racionalizar la sumisión de sus adeptos. De la mano de Kant puede comprenderse claramente esta idea: "los oficiales que dicen a sus soldados: no razonen, obedezcan; el del sacerdote que dice a los fieles: no razonen, crean, y el del funcionario fiscal que 
dice: no razonen, paguen" (Foucault, 2009, p. 51). Si el interés es la obediencia institucional incuestionable, entonces es claro que allí no existe ninguna clase de decir veraz, pues la utilidad de su decir es hacer indiscutible el poder del dominio institucional al cual representa. Dentro de este escenario, es de resaltar que no existe ninguna clase de honestidad intelectual: "Se ha vuelto un lugar común en el mundo moderno considerar al intelectual como extrañado, inadaptado y descontento. [...] nos hemos acostumbrado cada vez más a ver a nuestros intelectuales como no integrados, tábanos, hombres marginales y cosas parecidas" (Jay, 1989, p. 51).

Todo aquel quien ha naturalizado la mentira fija sus ojos con extrañeza ante quien enuncia la verdad. Pues es natural que en un mundo institucionalizado que legitima una vida segura, útil y equilibrada, sea esta lógica entendida como la única forma racional. Que este estilo de vida sea necesario no significa que sean algo (Cf. Bataille et al., 2005: 22).

Ahora bien, desde el sentido estricto de la palabra, aquel sacerdote conocedor de los textos sagrados, hábil orador, puesto a los intereses institucionales, no es un intelectual y mucho menos un parresiasta. Desde la óptica Nietzsche, el sacerdote es más cercano a un hábil embaucador:

Mientras el sacerdote este negador, este calumniador y envenenador profesional de la vida, siga siendo considerado como una especie de hombre superior, a la pregunta: ¿qué es la verdad? no hay respuesta. La verdad ya ha sido volteada, cuando el consciente abogado de la nada y de la negación fue considerado un representante de la verdad (Nietzsche, 2014, p. 14).

¿Qué es la verdad?, a que se le asocia, ¿de qué depende? ¿Nace de una preocupación? Y si a lo verdadero se le ha asociado con el cambio que tan correcto es afirmar que: "verdadero es todo aquello que promueve un cambio social en la dirección de una sociedad racional" (Horkheimer \& Adorno, 1994, p. 116).

\section{El decir veraz a partir de un caso colombiano}


Recordemos, lo que Sócrates predicaba, no me subí a una tribuna porque de haberlo hecho estaría muerto. No fue el hablar franco en la tribuna política lo que lo condeno, fue el ejercicio de la verdad lo que lo hizo. Ahora bien, en sincronía con esta perspectiva y alrededor de un escenario político contemporáneo colombiano, es menester señalar una figura del hablar franco que cautivo y concientizo con su humor y denuncia a los ciudadanos colombianos. Se trata del emblemático abogado y periodista Jaime Garzón. Personaje comprometido con la política, uso sus capacidades escénicas para encarnar e imitar personajes políticos. En la parodia y en la imitación encontró "una manera de revelar los resortes ocultos de una personalidad, es un espejo que agranda los defectos físicos y morales de personajes frente a los cuales el público toma distancia y se divierte" (Salazar, 2011, p. 107). Su personaje más emblemático en la televisión recibió el nombre Heriberto de la Calle, era un lustra botas que formulaba locuaces preguntas, pero también evocaba inteligentes respuestas cargadas de inminente franqueza. Sus entrevistas a personajes públicos, toco puntos álgidos de la política colombiana, entre ellos la corrupción política, el barbarismo guerrillero y paramilitar, el servilismo de Colombia hacia el imperio norteamericano y el celibato sacerdotal (Cf. Salazar, 2011, p. 107). Garzón desplego sus críticas a un campo que traspaso los límites de las fronteras, la televisión catapulto muchas de sus sátiras a diferentes rincones de Colombia y del mundo. De alguna forma, sus denuncias impregnadas de humor incomodo a los anteriormente nombrados. El humor, para Garzón era el estímulo para entretener, pero en especial para decirlo todo, pues: "el humor es un recurso para ganar el placer a pesar de los afectos penosos que lo estorban" (Freud, 1991, p. 216). Verdad y humor fueron el binomio de la enunciación veraz, un humor tan serio bañado en el descontento social, "el humor que sonríe entre lágrimas" (Freud, 1991, p. 220).

La manifestación humorística de Garzón está ceñida a los problemas de una realidad nacional, para él era claro que las criticas tienen que hacerse lejos de los intereses del poder por desprecio mismo a ese poder. También desdeñaba el tipo de moral colombiana, criticaba la manera como las personas se escandalizan por una palabrota en televisión, pero no se perturban, cuando 
hay niños que trabajan y piden limosna en las calles. En la comedia, Garzón encontró la manera de juzgar una realidad trágica y naturalizada, era un humor que conducía a "captar y enjuiciar la realidad desde un modo cómico, risueño o ridículo de las cosas" (De los reyes, 2011, p. 27). Aunque muchas veces su humor para muchos represento solo la manera de sobrellevar y dejar de lado situaciones tensas que desgasta la mente y cuerpo en los trajines de la cotidianidad. De ahí que Nietzsche, este en lo correcto cuando enuncia que el hombre sufre tan terriblemente en el mundo que se ha visto obligado a inventar la risa.

"El chiste es un juicio que juega" (Fischer citado en Freud, 1991, p. 220). En muchas ocasiones es un juego de palabras que esconde ironía envuelta en verdad. Sin embargo, cabe la posibilidad, de que el poder de denuncia se desvanezca a medida que cesan las risas de los espectadores. El humor de Garzón y sus irreverencias declaran verdades claras, honestas y sin tapujos que, bañadas de la cualidad parresiasta del peligro terminan siendo censuradas con su asesinato el día13 de agosto de 1999.

\section{A modo de cierre}

En la tradición griega, la verdad constituyó un estilo de vida para una elite hombres, para quienes su enunciación fue su heraldo. La verdad instaura la apertura a un mundo extraño lleno de indiferencia y hostilidades. Ante dicho contexto el parresiasta hace que su discurso sea el desvelamiento de la mentira. El lugar empleado para la enunciación de la verdad, fueron las calles y las asambleas públicas; en dichos espacios el hombre griego hacia resonancia de su discurso de razón. En nuestros tiempos, los medios de comunicación amplían la audiencia de quienes reciben el discurso veraz. Sin embargo, en ambos prevalece el mismo principio arcaico: el peligro de muerte.

Es así, como el cuidado de si y de los otros se mueve a favor de los hombres de verdad, pues quienes la enuncian busca transgredir los falsos discursos de poder. Es importante resaltar que la competencia de esta tarea se posa en las manos del parresiasta, pues cuando habla, se centra en lo que denuncia y no habla de cualquier cosa. Su discurso es alethurgia, porque conjura las fuerzas que 
se oponen a lo oculto, desentraña lo falso y hace posible lo inexpresable. Esta actitud corresponde a quien se preocupa por el futuro y no huye de las circunstancias, se relaciona a un modo de existencia que es fruto de comprender la realidad inconsecuente, en otras palabras, es una manera propia de ser.

Otra cualidad del parresiasta es que se rehúsa a ser despersonalizado, encara y asume las consecuencias de su verdad. En su decir no piensa la verdad como concepto sino como práctica, y esta praxis es básicamente apertura, pues al estar abierta al descubrimiento de lo oculto pone en evidencias las contradicciones de la realidad.

El empeño de buscar la verdad en las contradicciones, o en las cosas que no siempre se presentan claramente, es un punto de partida; es obvio que no solo el parresiasta es quien intenta desocultar una verdad, cualquiera tiene tal posibilidad, todo depende del escenario y del contexto. Ahora bien, para contextualizar un ejemplo de aquella búsqueda de la verdad fuera del marco parresiasta, me valdré del caso Heidegger. Precisamente, con la controvertida pertenencia de este filósofo al partido nacionalsocialista. Por eso, apoyado del intercambio epistolar entre Heidegger y Marcuse, se pondrá en contexto, dialogo el deseo de Marcuse por dar claridad a la tan cuestionada actitud de su colega.

Todo comienza con la carta que escribe Marcuse a Heidegger el 28 de agosto de 1947, Marcuse expresa desde su introducción su deseo de referirse al tema francamente. Esta epístola hace memoria de la conversación que tuvieron ambos filósofos en Todtnauberg, (Selva Negra). En ella, Marcuse hace reminiscencia de las palabras de Heidegger. Resalta como en el año de 1934, había hecho fuertes críticas al régimen, y que a consecuencia de ello era vigilado por la Gestapo. Marcuse le recuerda que, en el año de 1933, él se identificó enérgicamente con la el partido nacionalsocialista8: "Tus discursos, escritos y tratados de este periodo son la mejor prueba de ello.

\footnotetext{
${ }^{8}$ En la carta de Heidegger a Marcuse, 20 de enero de 1948, el filósofo de la Selva Negra le responde: "Con relación a 1933: yo esperaba del nacionalsocialismo una renovación espiritual de la vida en su totalidad, una reconciliación de los antagonismos y un redimir el Dasein occidental de los peligros del comunismo" (Marcuse, 2001, p. 313). Esta explicación Marcuse la refuta en la carta del 12 de mayo de 1948, al preguntarle a Heidegger: "¿Tú, el filósofo, confundiste la
} 
Nunca te has retractado de manera pública de ellos ni siquiera después de 1945" (Marcuse, 2001, p. 312). Ahora bien, ¿cómo explicar esta actitud del filósofo más importante del siglo XX? Bien podríamos entender que Marcuse le exige a Heidegger una actitud alethurgica capaz de hacer explicable lo inexplicable.

Entre otras cosas, Marcuse también le discute el haberse quedado en Alemania después de su explicita inconformidad con el régimen en 1934, Marcuse lo interpela expresándole que un intelectual como él podría haber encontrado trabajo en el mundo académico sin ninguna clase de problema. También le reclama su incapacidad de denunciar públicamente las atrocidades del régimen". Marcuse concluye que debido a estas razones aún lo identifican como nazi: "El sentido común (también entre intelectuales), que es testigo de tal resistencia, se niega a considerarte filósofo, porque la filosofía y el nazismo son irreconciliables. En esta convicción se justifica el sentido común" (Marcuse, 2001, p. 313). A mi modo de entender, la correspondencia entre el decir y el actuar no son independientes, pues ambas se complementan mutuamente para configurar el sentido común. Desvincularlas realzaría expresiones falaces o verdades fragmentadas. De ahí que el reclamo de Marcuse este sostenido en la base del sentido común, pues él cree que Heidegger no lo ha dicho todo.

Por falta de una verdad clara, el filósofo de la selva negra puede ser catalogado de diseccionar la existencia humana en sus textos, pero nunca de traspasar sus cubiertas. Solo una verdad explicita y franca depuraría toda clase de prejuicio. El interrogante que ha inquietado a muchos intelectuales es ¿por qué, Heidegger se niega a exponer públicamente las razones que lo pueden ratificar o absolverlo de su vínculo con el régimen nazi?

liquidación del Dasein occidental con su renovación? ¿No era esta liquidación evidente ya en cada palabra de los "líderes", en cada gesto y hazaña de la SA, mucho antes de 1933?" (Marcuse, 2001, p. 315).

${ }^{9}$ Dice Heidegger; En 1934 reconocí mi error político y renuncié al rectorado en protesta contra el Estado y el partido. Que las actividades partidistas de Heidegger fuesen explotados con propósitos propagandísticos tanto aquí como en el exterior, y que su renuncia también fuera silenciada por razones igualmente propagandísticas, no me di cuenta y no pueden argüirse en contra mía (Cf. Marcuse, 2001, p. 314). . 
Al respecto, Heidegger, en su carta a Marcuse del 20 de enero de 1948, dice: "no expresé una réplica pública, y eso es fácilmente comprensible; habría sido el final mío y de mi familia. En este punto Jaspers dijo: que permanezcamos vivos es culpa nuestra" (Marcuse, 2001, p. 313). Con su respuesta, Heidegger evidencia que el cuidado de si y de otros se restringe a sí mismo y su círculo familiar, lo cual es comprensible debido al contexto histórico al que Heidegger perteneció. En cambio, el cuidado de si y de otros, fue muy importante para los parresiasta de la época clásica, debido a que con su decir defendían los intereses de todos los ciudadanos. La verdad, respondía para ellos a necesidades sociales, históricas y políticas, su enunciación depende de factores internos y externos que juegan en contexto.

Se concluye que el intercambio epistolar entre Marcuse y Heidegger evidencian una carencia de la práctica parresiasta, pero si, una clara enunciación a modo privado de la verdad. El silencio prudencial de Heidegger lo acerca más a la figura del sabio. Sin embargo, Heidegger recurre a su vida académica, como herramienta que le permite validar su idea de verdad:

En mis conferencias y cursos de 1933-1944 incorporé un punto de vista tan inequívoco que entre los que eran mis estudiantes ninguno cayó víctima de la ideología nazi. Mis trabajos de este período, si aparecen algún día, darán testimonio de este hecho (Marcuse, 2001, p. 313).

\section{Referencias:}

Bataille, G; et. al. (2005), Acéphale, Buenos Aires, Caja Negra.

Foucault, M. (2010). El coraje de la verdad. Buenos Aires: Fondo económico de la cultura.

Foucault, M. (2009). El gobierno de si y de los otros. Buenos Aires: Fondo De Cultura Económica.

Foucault, M. (2004). Discurso y verdad en la antigua Grecia. Buenos Aires: Paidós.

Freud, S. (1991). El chiste y su relación con lo inconciente. Obras completas. Buenos Aires: Amorrortu, Volumen VIII.

Derrida, J. (1997). Historia de la mentira: Prolegómenos. Buenos Aires: Ediciones de la Oficina de Publicaciones del CBC de la UBA. 
De los reyes, D. (2011). Del humor y la risa en la filosofía griega antigua. Revista de filosofía, (24), 23 $-40$.

Davidson, D. (1997). Estructura y contenido de la verdad. Madrid: Tecnos.

Horkheimer, M; Adorno, T. (1994). Dialéctica de la ilustración, Madrid: Trotta.

Jaeger, W. (2001). Paideia: los ideales de la cultura griega. México DF. Fondo económico de cultura. Jay, M. (1989). La imaginación dialéctica. Madrid: Taurus.

Marcuse, H (2001). Guerra, tecnología y fascismo: textos inéditos. Santafé de Bogotá: Universidad de Antioquia.

Nietzsche, F. (2014). El Anticristo. Santafé de Bogotá: Panamericana.

Nietzsche, F (2004). Ecce homo: how one becomes what one is. United States: Algora.

Nietzsche, F. (2000a). Sobre el porvenir de nuestras instituciones educativas. Barcelona: Tusquets.

Nietzsche, F. (2000b). Voluntad de poder. Madrid: Edaf.

Platón. (1871). Obras completas: Apología de Sócrates. Recuperado de http://www.filosofia.org/cla/pla/img/azf01043.pdf

Salazar, J. (2011). Colombia: ¿Un país dónde se muere en vano? Una interpretación antropológica de la vida y obra del humorista Jaime Garzón (1960-1999). Análisis político, 24 (72), 101 - 114. 